\title{
UM OLHAR SOBRE UMA PROPOSTA DE FORMAÇÃO INICIAL DE PROFESSORES VOLTADA PARA AS ESTRATÉGIAS DE LEITURA
}

\author{
AN OVERVIEW OF A PROPOSAL FOR EARLY TEACHER TRAINING AIMED \\ TOWARDS READING STRATEGIES
}

\author{
Aline Diesel ${ }^{1}$ \\ Kári Lúcia Forneck ${ }^{2}$ \\ Eniz Conceição Oliveira ${ }^{3}$ \\ Marli Teresinha Quartieri ${ }^{4}$ \\ Silvana Neumann Martins ${ }^{5}$
}

\section{Resumo}

Este artigo surge no escopo do debate acerca da formação de professores comprometidos com a habilidade de leitura dos seus alunos. Tem como propósito apresentar e analisar uma proposta desenvolvida num programa de formação inicial de professores de Língua Portuguesa, a qual contemplou o ensino da compreensão leitora. Este trabalho está ancorado nos estudos de Solé (1998) e Kato (1985), que tratam das estratégias de leitura, e em Nóvoa (2009), Pimenta (2005), Tardif (2012), Borges (2011), entre outros, que abordam aspectos acerca da formação de professores. A partir de uma pesquisa de abordagem qualitativa, averiguou-se que a proposta desenvolvida trouxe contribuições significativas para a composição de saberes disciplinares dos futuros docentes de linguagem. As reflexões decorrentes da proposta confirmam a hipótese de que a melhora na qualidade da formação dos alunos no que diz respeito à leitura está atrelada à qualificação da formação dos professores de Língua Portuguesa. Além disso,

\footnotetext{
1 A autora é Mestranda do Programa de Pós-Graduação em Ensino do Centro Universitário UNIVATES. Bolsista Prosup/Capes. E-mail: aline.diesel@hotmail.com

${ }^{2}$ A autora é Mestre em Linguística e Letras pela Pontifícia Universidade Católica do Rio Grande do Sul (2006) e Professor Assistente do Centro Universitário Univates. E-mail: kari@univates.br

${ }^{3}$ A autora é Doutora em Química pela Universidade Federal do Rio Grande do Sul, Brasil (2005) e Professor Titular do Centro Universitário Univates. E-mail: eniz@univates.br

${ }^{4}$ A autora é Doutora em Educação pela Universidade do Vale do Rio dos Sinos (2012), é Professora Adjunta do Centro Universitário Univates. E-mail: mtquartieri@univates.br

${ }^{5}$ A autora é Doutora em Educação pela Pontifícia Universidade Católica do Rio Grande do Sul, (2010) e Professora Adjunta do Centro Universitário Univates. E-mail: smartins@univates.br
} 
entende-se que preparar os futuros professores a desenvolver nos seus alunos as estratégias de leitura pode ser o caminho para melhorar o desempenho dos alunos brasileiros em avaliações de leitura.

Palavras-chave: Estratégias de leitura. Formação inicial de professores. Saberes docentes.

\begin{abstract}
This articles arises from within the scope of the debate over the training of teachers who are committed to their students' reading skills. Its purpose is to present and analyze a proposal developed during an early Portuguese Language teacher training program that included the teaching of reading comprehension. This paper is anchored on studies by Solé (1998) and Kato (1985) concerning reading strategies, and by Nóvoa (2009), Pimenta (2005), Tardif (2012), Borges (2011), among others, who cover aspects about teacher training. Through qualitative approach research, it has been ascertained that the developed proposal brought significant contributions towards the composition of subject expertise in future language teachers. The reflections that originated from the proposal confirm the hypothesis that improvements to student training quality where reading is concerned is harnessed onto the qualification in Portuguese Language teacher training. Moreover, it is understood that preparing future teachers to develop reading strategies with their students could be the path to improving Brazilian students' performance in reading evaluations.
\end{abstract}

Key-words: Reading Strategies. Early Teacher Training. Faculty expertise.

\title{
INTRODUÇÃO
}

O baixo desempenho dos alunos brasileiros em avaliações de leitura, como na Prova Brasil e no Programa Internacional de Avaliação de Estudantes (PISA), vem direcionando esforços para que alternativas sejam pensadas, de modo a melhorar esse quadro. Se atentarmos para a evolução do desempenho dos estudantes brasileiros no PISA dos últimos dez anos ${ }^{6}$, é possível visualizar uma

6 Dados extraídos de: <http://infograficos.oglobo.globo.com/educacao/os-resultados-do-pisa2012.html>. Acesso em 25 de maio de 2016. 
evolução singela. Em 2006, o país ocupava a $46^{\text {a }}$ posição, com 393 pontos. Em 2009, evoluiu a pontuação para 412 pontos, no entanto, caiu para a 53ạ posição. Já em 2012, com 410 pontos, caiu para 55 posição. Essa inconsistência revela que, embora a qualidade da leitura esteja sutilmente melhorando, os esforços não estão sendo materializados na mesma medida dos demais países, que estão conseguindo melhores resultados.

Já os resultados de 2013 da Prova Brasil - avaliação realizada em âmbito nacional, que avalia a capacidade de leitura e de resolução de problemas de estudantes de $5^{\underline{0}}$ e $9^{\circ}$ anos - revelam que a média dos estudantes brasileiros em fase de conclusão do Ensino Fundamental foi de 237,77 e a dos estudantes gaúchos foi de $248,42^{7}$. Isso significa que, numa escala de proficiência que considera os níveis 1 a 8 , esses estudantes enquadram-se, nada menos e nada mais, do que no nível 2 (PROVA BRASIL, 2013). Tendo em vista que a prova avalia especificamente as habilidades de leitura dos estudantes e não questões de nomenclatura gramatical, por exemplo, pode-se pressupor que os estudantes saem da escola com dificuldades para lidar com situações em que precisam interagir com as mais diversas situações de leitura com as quais se deparam.

Assim, possivelmente, os alunos brasileiros não interagiram com boas práticas de leitura ao longo da Educação Básica e, dessa forma, não foram ensinados a desenvolver habilidades de compreensão leitora.

O fato de não terem sido ensinados, muito provavelmente, pode ser decorrente da falta de conhecimentos sobre a abordagem dos próprios professores de Língua Portuguesa, os quais deveriam ter, como função inerente, o

\footnotetext{
${ }^{7}$ Dados disponíveis em <http://portal.inep.gov.br/web/saeb/resultados-2013>, no Boletim de Desempenho das escolas.
} 
propósito de desenvolver essa competência nos seus estudantes. O que se está querendo dizer é que, provavelmente, muitos professores não sabem como desenvolver a compreensão leitora em seus alunos.

A partir dessas constatações, presume-se que uma das causas desse cenário seja uma formação inicial incompleta, muitas vezes focada em teorias descontextualizadas da prática. Isto é, se os professores não sabem como desenvolver a compreensão leitora de seus estudantes, possivelmente não aprenderam como fazê-lo na graduação, o que condiz com o distanciamento entre a teoria acadêmica sobre o ensino de Língua Portuguesa e a prática pedagógica dos professores da disciplina no Ensino Fundamental e do Ensino Médio (OLIVEIRA, 2010). Assim, defende-se aqui a tese de que a melhora da qualidade da formação dos alunos está atrelada à qualificação da formação dos professores.

O resultado desse descompasso é o comprometimento da possibilidade de grande parte dos jovens de participarem ativamente da sociedade. Beddington et al. (2008) apontam para a importância de, desde cedo, oferecer estímulos positivos para que a criança desenvolva-se cognitivamente. Dentre esses estímulos está um olhar especial para o ensino da leitura, levando em conta o seu processamento cognitivo. De acordo com os autores, os benefícios não só seriam vistos no contexto educacional, como também trariam reflexos na redução da criminalidade, na produtividade no trabalho, na saúde, entre outros.

É preciso considerar também que a leitura aproxima os sujeitos da cultura e ao mesmo tempo contribui para que o aluno constitua-se como cidadão (SOLÉ, 1998). Ademais, "se ensinamos um aluno a ler compreensivamente e a aprender a partir da leitura, estamos fazendo com que ele aprenda a aprender, isto é, com 
que ele possa aprender de forma autônoma em uma multiplicidade de situações". (SOLÉ, 1998, p. 47).

Apesar de a temática da leitura ser constantemente revisitada em pesquisas acadêmicas, poucas são as investigações que tratam da interface entre os programas de formação inicial de professores e a composição de profissionais voltados para a leitura numa perspectiva cognitiva, que é o que se pretende nesta escrita.

Tendo em vista essas considerações, tem-se como propósito, neste artigo, apresentar e analisar uma proposta de formação inicial de professores de Língua Portuguesa voltada para o ensino da compreensão leitora.

Cabe mencionar que este trabalho teve sua gênese durante a disciplina Estágio de Docência8 ${ }^{8}$ do mestrado do Programa de Pós-Graduação em Ensino. O estágio foi desenvolvido na disciplina Psicolinguística, do curso de licenciatura em Letras, e teve como foco o tópico estratégias de compreensão leitora, a partir de Solé (1998). A turma era composta por 24 estudantes, de semestres variados. Uma das alunas era formanda do curso de Pedagogia e optou por cursar essa disciplina como eletiva.

$\mathrm{Na}$ próxima seção, abordam-se pressupostos da formação inicial de professores e tecem-se algumas considerações especificamente voltadas à formação de docentes de Língua Portuguesa. Essas considerações dão fundamento à proposta desenvolvida numa disciplina do curso de Letras, direcionada às estratégias de leitura.

\footnotetext{
${ }^{8}$ De acordo com a Portaria/Capes 190, de 17/09/2010, o Estágio de Docência no Ensino Superior é requisito obrigatório para mestrandos e doutorandos que recebem bolsa da Coordenação de Aperfeiçoamento de Pessoal de Nível Superior (Capes).
} 


\section{PRESSUPOSTOS TEÓRICOS}

O referencial teórico que fundamenta este artigo percorre pressupostos acerca da formação de professores, sustentados por Nóvoa (2009), Veiga e Viana (2011), (Borges, 2011) e Tardif (2012). Na sequência, são apresentados alguns aspectos em relação à formação de professores especificamente de Língua Portuguesa, defendidos especialmente por Antunes (2009). Feito isso, articulamse alguns aspectos em relação a estratégias de compreensão leitora e como deve se dar a formação para tal abordagem.

\subsection{Formação inicial de professores}

O contexto atual de avanços tecnológicos cada vez mais velozes, de problemas sociais, políticos, econômicos requer sujeitos com características diversas, tais como conhecimento, criatividade, proatividade e, sobretudo, habilidades afetivo-emocionais.

Entre várias mudanças no sistema educacional nos últimos anos, implementadas no intuito de atender essas exigências atuais, destaca-se a Lei de Diretrizes e Bases da Educação Nacional (LDB 9394/1996), que passou a exigir a formação em curso superior do professor. Com essa condição, acreditou-se ter um profissional mais preparado para atender os alunos, melhorando a qualidade da educação brasileira como um todo.

Contudo, transcorridos vinte anos de sua publicação, e com a implementação de políticas públicas voltadas para a formação inicial e continuada de professores, percebe-se que ainda há um longo caminho a percorrer quando o assunto é formação de professores. Embora muitos sejam os estudos nessa área, muito ainda se tem o que pesquisar. 
A atividade cotidiana do professor é ensinar. Ele não trabalha um objeto, como um operário de uma indústria, mas trabalha com um sujeito, o aluno, transformando-o, educando-o e instruindo-o (TARDIF, 2012). De acordo com o autor (2012, p.13), “Ensinar é agir com outros seres humanos que sabem que lhes ensino; é saber que ensino a outros seres humanos que sabem que sou um professor".

Diante disso, o docente na contemporaneidade requer uma gama de atribuições, como habilidades, técnicas e competências para a sua prática com jovens estudantes. Sua ação requer, sobretudo, inúmeros saberes, para além daqueles ensinados aos professores ao longo de sua formação. Alguns estão diretamente ligados à experiência da prática do trabalho, nas atividades de interação humana, entre pessoas que constituem os seus movimentos de ação docente.

O saber dos professores, para Tardif (2012, p. 11), é algo articulado por meio da sua identidade, da sua história de vida, das suas experiências:

[...] o saber não é uma coisa que flutua no espaço: o saber dos professores é o saber deles e está relacionado com a pessoa e a identidade deles, com a sua experiência de vida e com a sua história profissional, com as suas relações com os alunos em sala de aula e com os outros atores escolares na escola, etc. Por isso, é necessário estudá-lo relacionando com esses elementos constitutivos do trabalho docente.

Assim, ensinar supõe também aprender a ensinar, já que, de acordo com o autor, não se reduz a transmitir conhecimentos já constituídos. Para tanto ensinar, o docente vale-se de saberes essenciais oriundos da sua formação profissional e de saberes experienciais, disciplinares e curriculares. (TARDIF, 2012).

Os 'saberes experienciais' são um conjunto de saberes adquiridos na prática da ação docente, por meio da interação com as pessoas. São baseados no trabalho 
cotidiano do professor e no conhecimento com o seu meio, incorporando a experiência individual e coletiva do saber-fazer e saber-ser. Possuem três objetos: as relações e interações que os professores estabelecem e desenvolvem com os demais atores no campo da sua prática; as diversas obrigações e normas às quais seu trabalho deve submeter-se; e, por último, a instituição enquanto meio organizado e composto de funções organizadas. (TARDIF, 2012).

Pimenta (2005) também se reporta aos saberes da experiência como sendo aqueles adquiridos ao longo da vida escolar, enquanto alunos, que possibilitam “dizer quais foram os bons professores, quais eram bons em conteúdo mas não em didática, isto é, não sabiam ensinar" (PIMENTA, 2005, p. 20). De acordo com a autora, os saberes da experiência também são aqueles produzidos pelos próprios professores ao longo da prática docente, num processo de constante reflexão sobre a própria prática.

Os 'saberes curriculares', conforme apresentado por Tardif (2012), são aqueles saberes que correspondem aos discursos, objetivos, conteúdos e métodos a partir dos quais a instituição escolar se baseia e que os professores devem aprender a utilizar.

E, 'os saberes disciplinares' são saberes sociais definidos e selecionados pelas instituições universitárias ao longo da formação inicial e continuada do professor. São saberes que correspondem aos diversos campos do conhecimento, que compõem as disciplinas dos cursos de formação. (TARDIF, 2012).

A ação do professor deve orientar e facilitar a interação do estudante com a informação, para que este possa apropriar-se de conhecimentos, o que irá, efetivamente, contribuir para a sua inserção e ação na sociedade atual. A partir dessa perspectiva, vislumbra-se, nos cursos de formação inicial de professores, 
"um currículo capaz de fazer o futuro professor aprender a ensinar em condições favoráveis para que os seus futuros alunos também aprendam”. (BORGES, 2011, p. 39).

Veiga e Viana (2011), dentro da discussão acerca da formação de professores, entendem que ela assume um papel que transcende aspectos teóricos e pedagógicos. De acordo com as autoras, a formação docente precisa preocuparse com uma escola que questione sua função social e sua responsabilidade em relação aos problemas educativos do contexto em que ela está inserida. A isso estão atrelados diversos elementos que não devem ser menosprezados, entre os quais destacam-se a diversidade apresentada no dia a dia da escola e o estímulo a uma atitude indagadora e crítica tanto à própria prática, quanto das propostas educativas e da instituição. (VEIGA; VIANA, 2011).

Como uma possibilidade à formação fragmentada, individualista e antidemocrática, decorrente da própria sociedade que tem sido pautada nesses valores, Borges (2011) compreende a necessidade de se instaurar uma perspectiva integradora na formação docente, abarcando a relação entre conteúdo e método, entre teoria e prática, e a integração entre a educação superior e a básica.

[...] um professor comprometido com uma educação verdadeiramente emancipatória prima por ser um detentor de saberes acadêmicos e profissionais que vão muito além do seu repertório cotidiano da sala de aula, isto é, ele é capaz de superar o que ensina. (BORGES, 2011, p. 37).

O autor também volta-se para a necessidade da prática investigativa nos processos de formação de docentes:

A formação docente por meio da pesquisa torna-se, assim, componente curricular referencial para o futuro professor compreender a realidade na qual se insere a fim de poder transformá-la, quando necessário, o que evidencia uma postura problematizadora e, ao mesmo tempo, propositiva. (BORGES, 2011, p. 37). 
Essa conduta problematizadora e propositiva, de certa forma, articula-se com o pensamento de Nóvoa (2009). O autor entende que o trabalho do professor consiste no desenvolvimento de práticas que levem os alunos à aprendizagem. Contudo, ele tece uma crítica pertinente aos programas de formação de professores, os quais, segundo o autor, estão muito afastados da profissão docente, das suas rotinas e culturas profissionais. Com esse posicionamento, o autor relaciona cinco propostas de trabalho a partir das quais os programas devem ser pensados:

- Assumir uma forte componente prática, centrada na aprendizagem dos alunos e no estudo de casos concretos, tendo como referência o trabalho escolar;

- Passar para «dentro» da profissão, baseando-se na aquisição de uma cultura profissional e concedendo aos professores mais experientes um papel central na formação dos mais jovens;

- Dedicar uma atenção especial às dimensões pessoais da profissão docente, trabalhando essa capacidade de relação e de comunicação que define o tacto pedagógico;

- Valorizar o trabalho em equipa e o exercício coletivo da profissão, reforçando a importância dos projetos educativos de escola;

- Caracterizar-se por um princípio de responsabilidade social, favorecendo a comunicação pública e a participação profissional no espaço público da educação. (NÓVOA, 2009, p. 1)

De acordo com o entendimento do autor, a formação de professores deve ser construída dentro da profissão, ou seja, integrando saberes científicos, pedagógicos e técnicos. Como é possível perceber no excerto acima, o autor valoriza os docentes mais experientes, os quais devem ser tidos como âncoras dos próprios colegas.

Feitas essas considerações teóricas acerca da formação de professores, passa-se, na próxima etapa, a analisar como se dá, ou como deveria se dar, especificamente, a formação de professores que têm a função de ensinar a compreensão leitora. 


\subsection{Formação de professores de Língua Portuguesa}

Levando em consideração que a linguagem é uma valiosa ferramenta para “construir nossa concepção de mundo, para imaginar, interpretar, organizar, abstrair, etc. será preciso pensar em um programa educativo que ajude a ampliar essas capacidades a partir de sua ancoragem em experiências plenas de sentido". (COLOMER; CAMPS; MURAD, 2002, p. 28-27).

Assim, os programas de formação de docentes devem prever uma educação linguística ampla, em que o enfoque em normas gramaticais dê lugar à compreensão textual. Nessa abordagem de privilegiar os sentidos dos textos, Antunes (2009, p.42) prevê que a gramática surgirá naturalmente.

O foco seria a compreensão e a produção dos sentidos materializados em gêneros de textos, com grande destaque para a literatura. A gramática viria naturalmente (não poderia deixar de vir!), quando fosse necessário para que pudesse entender melhor a passagem ou expressar com mais propriedade o que se quer dizer. Viria, ainda, quando fosse necessário apreender ou avaliar as normas do uso formal da língua, conforme as exigências sociais em questão.

A autora entende que, além desse olhar amplo, o ensino de línguas deve levar em conta a formação cidadã do aluno:

Primeiramente, estimulando o senso crítico do aluno por meio de múltiplas atividades de análise e de reflexão; instigando a curiosidade, a procura a pesquisa, a vontade da descoberta, o que implica a não conformação com o que já está estabelecido; desestimulando, portanto, o simplismo e o dogmatismo com que as questões linguísticas têm sido tratadas. (ANTUNES, 2009, p.43).

Diante disso, há de se convir que, se a atividade docente deve preocupar-se com o senso crítico do aluno, essa prática também precisa ser privilegiada nos programas de formação. É preciso abandonar a abordagem tradicional de 
transmissão exclusiva de conteúdos gramaticais que muitos ainda executam, objetivando suprir as lacunas dos estudantes, advindas na Educação Básica.

Essa transposição para uma abordagem mais contemporânea, com olhar para a formação crítica do aluno, também deve dar lugar ao ensino da leitura, a partir de uma perspectiva cognitiva. Muito já se pesquisou e muitas ações já estão sendo desenvolvidas, tanto no âmbito da formação de professores quando na esfera escolar, sobre a leitura na perspectiva literária (RÖSING; ZILBERMANN, 2016; LAJOLO, 2013). Contudo, percebe-se a carência de estudos e de ações sobre o preparo dos futuros professores para lidar com situações de aprendizagem para o processamento da leitura e sobre as estratégias que podem aprimorar essa habilidade, numa perspectiva psicolinguística. É justamente o que este estudo se propõe, aspecto no qual se configura a originalidade do trabalho.

Mas o que seriam essas estratégias de compreensão leitora? Por que elas deveriam ser abordadas nos cursos de formação inicial e, consequentemente, ensinadas nas escolas? Afinal, os alunos dos anos finais do Ensino Fundamental já não sabem ler? A próxima seção trata de responder essas questões.

\subsection{Estratégias de compreensão leitora}

Neste estudo, a compreensão leitora extrapola a habilidade de decodificar e de ler fluentemente. Parte-se da perspectiva de que a leitura é um processo cognitivo realizado pelo leitor, a partir do qual busca-se produzir sentidos, levando em conta conhecimentos prévios e objetivos acerca do conteúdo lido e as pistas linguísticas deixadas pelo autor, havendo, assim, a interação leitor/texto/autor (KATO, 1985; PEREIRA, 2009). Para tal, o professor de Língua Portuguesa no Ensino Fundamental deve conhecer os caminhos utilizados pelo 
leitor para compreender o que está lendo. Esses caminhos envolvem processos cognitivos e estratégias que ele adota para aprimorar a habilidade de leitura.

De início, convém esclarecer que aprender a ler não é fácil e dificilmente se dá de forma espontânea. Caso assim fosse, não teriam tantos analfabetos e, o que é mais grave, não teria um percentual tão elevando de analfabetos funcionais, isto é, de sujeitos que frequentaram a escola por anos e não compreendem o que leem, mesmo estando expostos a palavras escritas nos mais variados lugares ou suportes, como nas telas da televisão. (MORAES, 2013).

Moraes (2013) justifica esse quadro ao fato de não terem sido ensinados a ler. Muitos foram ensinados apenas a decodificar, mas não a ler, que envolve, na verdade, "capacidades cognitivas gerais, como a atenção, a ativação de conhecimentos prévios, a memória de trabalho ativada, a inferenciação, e de capacidades linguísticas, como acessar a significação básica, processar metáforas e outras figuras, construir o sentido, recuperar anáforas". (MORAES, 2013, p. XX).

Para avançar na discussão, cabe explicar melhor o que se entende por estratégias e as modalidades de estratégias relevantes para a leitura. Estratégias de leitura são consideradas habilidades usadas para promover a compreensão leitora; são procedimentos ou atividades que facilitam o processo de aquisição de informações, variando de acordo com o texto a ser lido. (ALVES, 2008).

Solé (1998, p. 71) explica que o leitor proficiente utiliza as estratégias de forma inconsciente; o processamento de informação escrita que o ato de leitura requer acontece, para leitores habilidosos, de maneira automática. Nesse percurso, o leitor utiliza-se das estratégias cognitivas. Entretanto, quando encontra algum obstáculo, como uma frase incompreensível, um desenlace inesperado que contradiga as expectativas, uma página colocada de forma 
incorreta, o leitor recorre às estratégias metacognitivas. Nessas situações, o leitor proficiente dispõe uma atenção especial e realiza determinadas ações, como reler o contexto da frase, examinar as premissas em que se baseiam suas hipóteses sobre qual deveria ser o final do romance, etc. São casos em que o leitor utiliza-se de estratégias de forma completamente consciente.

Para esclarecer essa diferenciação entre as estratégias cognitivas e as metacognitivas, cabe uma citação de Leffa (1996, p. 45):

A metacognição envolve, portanto, (a) a habilidade para monitorar a própria compreensão ('Estou entendendo muito bem o que o autor está dizendo', 'Esta parte está mais difícil mas dá para pegar a ideia principal.') e (b) a habilidade para tomar as medidas adequadas quando a compreensão falha ('Vou ter que reler este parágrafo', 'Essa aí parece ser uma palavra chave no texto e vou ter que ver o significado no glossário').

Para clarificar ainda mais o que envolve a cognição e a metacognição, o autor traz o exemplo da leitura de um romance em que o leitor está concentrado nos acontecimentos narrados. Quando a leitura segue um ritmo acelerado e o leitor concentra-se apenas no enredo, ele não tem nenhuma consciência do processo da leitura, mas se concentra no efeito da leitura. Contudo, quando se dá conta de que houve um problema de compreensão e de que precisa tomar uma atitude para corrigi-lo, ocorre uma atividade metacognitiva.

As estratégias cognitivas merecem atenção quando se trata da aquisição da linguagem. Contudo, de acordo com Kato (1985), as metacognitivas merecem um interesse especial para a aprendizagem formal nas demais etapas da Educação Básica, especialmente nos anos finais do Ensino Fundamental, em razão de sua natureza consciente.

Cabe mencionar que, embora se reconheça a importância do enfoque didático nas estratégias metacognitivas, a proposta aqui apresentada versa, de 
modo mais abrangente, sobre as estratégias de leitura apresentadas por Solé (1985). A autora, apesar de mencionar a metacognição, não faz a distinção entre quais das estratégias são metacognitivas ou cognitivas. Destaca-se, ainda, que, na disciplina em que esta proposta foi desenvolvida, essa diferenciação foi o próximo ponto de discussão.

Solé (1998) classifica as estratégias de leitura em três grupos: estratégias antes da leitura, estratégias durante a leitura e estratégias após a leitura. Entre as estratégias antes da leitura, estão as seguintes: ativação de conhecimentos prévios, definição de objetivo de leitura, predição. As estratégias durante a leitura são: seleção, predição, direcionamento da atenção, automonitoramente, ativação do conhecimento prévio, inferenciação, entre outros. Já entre as após a leitura, citam-se: sumarização, identificação da ideia principal.

De acordo com Solé (1998), a escola precisa ensinar as estratégias de leitura. Contudo, ela mesma garante que essa divisão é meramente didática, já que muitas estratégias podem ocorrer praticamente simultaneamente.

Dada a importância da sua abordagem nas aulas de Língua Portuguesa, esse tema também deve ser enfocado nos programas de formação inicial, ou seja, nos cursos de licenciatura da área. A proposta que é apresentada na seção 3 pretende socializar uma forma de possibilitar este estudo com alunos da Licenciatura em Língua Portuguesa.

Os elementos teóricos apresentados até aqui serviram de suporte para sustentar a proposta desenvolvida. Na continuidade deste trabalho, percorre-se, na próxima seção, a descrição detalhada da proposta. 


\section{DESCRIÇÃO DA PROPOSTA DESENVOLVIDA}

A proposta foi desenvolvida em três aulas (turnos). A seguir, são apresentados os planejamentos, os quais, após, serão analisados a partir dos preceitos teóricos apresentados na seção anterior.

2.1 Primeira aula - objetivo: reconhecer as estratégias antes, durante e depois da leitura e a importância de ensiná-las nas aulas de Língua Portuguesa do Ensino Fundamental.

Para alcançar o objetivo proposto para esta aula, foi disponibilizado, com antecedência de uma semana, um artigo de revisão elaborado pela estagiária e revisado pela professora titular da disciplina, sobre o conteúdo da disciplina, qual seja as estratégias de leitura. A partir do texto lido, foi realizada uma atividade denominada Peer instruction. Para tal, foi utilizado o apoio do laboratório móvel da Instituição, de modo que cada aluno pudesse manusear um tablet. Além disso, antes do início da aula, as mesas foram dispostas pela estagiária em seis grupos de quatro alunos.

Ao dar início à dinâmica Peer instruction, os alunos estavam em grupos e cada um possuía um tablet. Depois da explicação sobre como realizar o acesso ao sistema, a estagiária liberou a primeira pergunta, previamente cadastrada no aplicativo socrative ${ }^{9}$, para que os alunos, individualmente, refletissem sobre a resposta e marcassem a alternativa considerada correta. Assim, com o apoio do software, a estagiária tinha o controle das respostas, ou seja, tinha acesso à resposta assinalada por cada aluno bem como ao percentual de acertos da turma.

\footnotetext{
9 Trata-se de um aplicativo gratuito disponível em www.socrative.com, no qual podem ser elaboradas perguntas de múltipla escolha, verdadeiro/falso ou abertas. Para tanto, o gerenciador, no caso o professor, cadastra-se no site, que irá gerar uma senha. Essa senha deve ser disponibilizada aos que devem acessar as perguntas.
} 
Num segundo momento, a mesma pergunta era liberada novamente pela estagiária para que os alunos discutissem-na nos pequenos grupos. Desse momento, na medida do possível, deveriam usar o poder de argumentação para convencer o colega de que estavam corretos. Ao chegarem a um consenso, todos os componentes do grupo deveriam marcar a mesma alternativa. Após todos os componentes do grupo terem assinalado sua resposta, a estagiária dava a resposta correta, e abria-se uma discussão acerca dessa alternativa e das demais, justificando o motivo de estarem incorretas.

As perguntas apresentadas para discussão nessa atividade estão apresentadas no Quadro 1, a seguir:

\section{Quadro 1 - Perguntas utilizadas na estratégia Peer Insctruction}

1) Antes de iniciar uma atividade de leitura, o professor já deve realizar mediações que irão influenciar na compreensão leitora dos alunos. Qual dos procedimentos abaixo não convém ser instigado em sala de aula?

a) Definir um objetivo para a leitura - irá auxiliar o professor na tomada de decisões referentes aos caminhos.

b) Motivar para a leitura - com atividades que estimulem a competição entre os alunos.

c) Ativar conhecimentos prévios - incentivando os alunos a falarem o que já sabem sobre o assunto do texto.

d) Estabelecer previsões sobre o texto - a partir do título, imagens, subtítulos, entre outros elementos.

2) Qual o assunto do texto?

Um jornal é melhor do que uma revista. Uma praia é melhor do que uma rua. A princípio é melhor correr do que andar. Talvez você tenha que tentar várias vezes. É necessário ter alguma habilidade, mas é fácil de aprender. Mesmo crianças pequenas se divertem com isso. Uma vez bem sucedido, as complicações são mínimas. Pássaros raras vezes chegam muito perto. Chuva, contudo, ensopa muito rápido. Gente demais fazendo a mesma coisa também pode causar problemas. Precisa-se de muito espaço. Se não houver complicações, pode ser muito calmo. Uma pedra servirá de âncora. Se elas se soltarem, você terá uma segunda chance.

3) Prestar atenção ao título do texto é uma importante estratégia de leitura, assim como a subtítulos, imagens... De que tipo?

a) Estratégias antes da leitura: predição leitora. 
b) Estratégias antes da leitura: inferência

c) Estratégias durante da leitura: automonitoramento

d) Estratégias durante da leitura: ativar conhecimentos prévios

e) Estratégias depois da leitura: revisão do texto.

4) “[...] provocar perguntas sobre o texto é uma estratégia que pode ser praticada em diferentes níveis de leitura" (SOLÉ, 1998, p. 113). Isso significa que é importante questionar o aluno desde os anos iniciais até os anos finais da Educação Básica. Também significa que qualquer tipo de texto permite fazer provocações: textos narrativos, textos informativos, textos instrutivos etc.

a) Verdadeiro.

b) Falso.

5) O trabalho em sala de aula deve objetivar a formação de um aluno ativo, que tenha consciência de seu processo de leitura. Isso significa que ele deve ser capaz de aprender autonomamente, identificando lacunas de compreensão e encontrando as soluções possíveis problemas de leitura.

Para tanto, o professor deve trabalhar estratégias durante e após a leitura. As estratégias antes da leitura não irão interferir diretamente na formação de um leitor ativo, pois apenas irão contribuir para aguçar a curiosidade do aluno, motivando-o para a leitura.

a) Verdadeiro.

b) Falso.

6) As estratégias de leituras propostas por Solé (1998) devem ser tratadas com uma determinada sequência temporal. Enquanto o aluno não for competente na fase inicial, não se deve passar para a próxima etapa.

a) Verdadeiro.

b) Falso.

7) Deparou-se com uma palavra da qual desconhece o significado: "signatário". Diante disso, ele tem as seguintes opções:

a) pode considerar que aquela palavra não seja importante para o contexto e continuar a leitura.

b) pode pausar a leitura e reler o trecho anterior, e tentar entender o significado da palavra pelo contexto.

c) pode considerar que esta é uma palavra essencial nesse texto e, portanto, para a leitura e procura o significado no dicionário.

Nesse contexto, qual seria a opção não essencial?

8) Solé (1998) apresenta três tipos de perguntas:

- perguntas que exigem resposta literal do texto,

- perguntas cuja resposta pode ser deduzida, exigindo que o leitor relacione diversos

elementos do texto e realize algum tipo de inferência,

- perguntas de elaboração pessoal, permitindo opinião do leitor a partir do texto.

Para a autora, o trabalho do professor deve ser centrado em perguntas que pressuponham 
respostas deduzidas, sendo que as demais não deveriam ser trabalhadas em sala de aula.

a) Verdadeiro.

b) Falso.

9) Não é necessário programar atividades específicas para a aprendizagem das estratégias. O ensino desses procedimentos deve estar subjacente ao trabalho do professor.

a) Concordo.

b) Discordo

10) O simples fato de o professor conhecer as estratégias e os benefícios do ensino da leitura não é fator predominante para alcançar êxito em projetos referentes a ela. Portanto, mais do que conhecer esse assunto, o educador terá de assumir uma postura modelo, isto é, tornar-se para os seus alunos um referencial no que diz respeito ao apreço pela leitura (BRODBECK; COSTA; CORREA, 2012, p. 106, adaptado).

a) Concordo.

b) Discordo

Fonte: Elaborada pelos autores, 2016.

Após o encerramento da atividade, houve uma discussão geral sobre as estratégias antes, durante e depois da leitura. Foram realizados questionamentos como: Quais são as estratégias que precisam ser estimuladas antes da leitura? E em relação às estratégias durante a leitura? E após a leitura?

Foi realizada, então, o último momento desta aula, a partir da leitura de uma transcrição de uma aula de Língua Portuguesa de $6^{0}$ ano (MARTINS NETO, 2015), que teve como foco o texto Meu tio Jules, de Guy de Maupassant. A transcrição foi lida pela estagiária e foram feitas pausas para comentar as estratégias e metodologias contempladas pela docente antes, durante e após a leitura do conto.

2.2 Segunda aula - objetivo: identificar se as estratégias de leitura aparecem em livros didáticos e perceber a importância da mediação do professor para complementar as orientações trazidas pelos livros didáticos. 
Para tanto, previamente, a estagiária selecionou oito capítulos (unidades) de livros didáticos, que foram digitalizados e disponibilizados no ambiente virtual da disciplina. Em grupos, os estudantes tinham que analisar os textos das unidades selecionadas, as instruções ao professor e os tipos de questionamentos feitos, a fim de verificar se aquela unidade contemplava as estratégias de leitura, na perspectiva de Solé (1998). Cada grupo contava com pelo menos um notebook e que os arquivos estavam disponibilizados em word para que os alunos pudessem inserir as constatações no próprio arquivo disponibilizado, utilizando os recursos "Inserir" - "Formas". Salienta-se, ainda, que foi entregue para cada grupo o livro didático do qual o capítulo/unidade foi retirado, a fim de facilitar a visualização de todo o material.

Após, foi desenvolvida a apresentação das constatações de cada grupo. Ao final das apresentações, a estagiária incitou uma discussão acerca da qualidade do livro didático. Será que vale a pena adotá-lo? Ou é o caso de aboli-lo da aula de Língua Portuguesa? As conclusões foram de que, de uma forma geral, as obras analisadas contemplavam textos significativos e que retratam uma boa sequência didática, pautada nas estratégias de leitura. Contudo, cabe ao professor atribuir significado àquelas atividades tendo em vista seus alunos.

2.3 Terceira aula - objetivo: transpor o conteúdo estratégias de leitura para a prática da sala de aula do Ensino Fundamental.

A estagiária preparou previamente um conjunto de dois textos de gêneros diferentes, mas que abordassem o mesmo tema. Um dos textos envolveu gêneros mais verbais, com apelo mais linguístico, como artigo de opinião, reportagem, conto, poema, entrevista; e o outro era um gênero que explorava também 
elementos não verbais, com apelo mais visual, como propaganda, charge, cartum, fôlder.

A partir dos textos disponibilizados, os alunos, em grupos de três, deveriam elaborar uma transposição didática que contemplasse estratégias antes, durante e após a leitura, articulando os textos. Essa transposição didática deveria ser entregue ao professor da disciplina e comporia uma etapa da avaliação final do semestre. Tratou-se de um planejamento que contemplasse o template disponibilizado: título, nome dos autores, turma/público alvo, duração, tema, conteúdos abordados, objetivo geral e específicos; fundamentação teórica, procedimentos, forma de avaliação e referências.

Também foram apresentados os critérios de avaliação, para que os alunos tivessem clareza, desde o início da atividade, o que seria levado em conta para a avaliação. Os critérios foram: adequação ao objetivo estipulado (60\%), adequação ao modelo proposto $(10 \%)$, envolvimento de todos os componentes do grupo (10\%), criatividade $(10 \%)$, coerência gramatical $(10 \%)$.

Assim seguiu-se a aula. Os grupos formaram-se e iniciaram a leitura e a análise dos textos. A estagiária passava nos grupos esclarecendo dúvidas, dando ideias, enfim, interagindo. Para que se sentissem no compromisso de iniciar a discussão e a elaboração do planejamento, foi solicitado que postassem no ambiente virtual, no final da noite, o que conseguiram produzir. Percebeu-se que os alunos avançaram nas discussões, mas não houve tempo para sistematização. Assim, estagiária e titular decidiram destinar um tempo na aula seguinte para a continuação da atividade. 


\section{ANÁLISE DA PROPOSTA DESENVOLVIDA}

Inicia-se a etapa da análise da proposta desenvolvida ressaltando a relevância de os licenciandos em Letras conhecerem as estratégias de leitura, a partir de Solé (1998), já que são princípios básicos para o ensino de habilidades de leitura. A partir desse trabalho, os futuros professores poderão direcionar-se para outras leituras para aprimorar o trabalho com seus alunos.

A proposta desenvolvida envolveu a reflexão teórica, por meio da leitura do artigo de revisão, análise de livros didáticos e a elaboração de transposição didática. Com isso, procurou-se aproximar a profissão docente das suas rotinas e culturas profissionais, conforme prevê Nóvoa (2009).

Na primeira aula, destacam-se os efeitos da dinâmica peer instruction. Por promover o debate em equipe, a reflexão e o poder de formulação de argumentos, entende-se também ter contribuído para o estímulo a uma atitude indagadora e crítica do futuro professor, conforme apontado por Veiga e Viana (2011).

Os alunos tiveram uma boa receptividade diante dessa atividade, pois participaram ativamente. A possibilidade de visualização das respostas marcadas pelos alunos, tanto individualmente, quanto em grupo, oportunizou verificar a evolução das discussões. Além disso, possibilitou o professor saber como estão sendo as aprendizagens e, em caso de necessidade, reconhecer e retomar algum ponto problemático para os alunos. Assim, entende-se que, aliando a dinâmica à leitura do artigo de revisão e a uma breve explanação geral do que seriam as estratégias antes, durante e depois da leitura, foi alcançado o objetivo proposto, qual seja, conhecer as estratégias antes, durante e após a leitura apresentadas por Solé (1998), e reconhecer a importância de estimulá-las na Educação Básica. 
A proposta de análise de recursos didáticos disponíveis aos professores de Língua Portuguesa condiz com a necessidade de uma atitude indagadora e crítica do professor diante da sua prática, como também das propostas educativas e da instituição (VEIGA; VIANA, 2011). Esse posicionamento concorda, também, com a perspectiva de Antunes (2011) apresentada anteriormente. De acordo com a autora, deve-se estimular o senso crítico do aluno, seja ele licenciando ou estudante da Educação Básica, por meio de múltiplas atividades de análise e de reflexão.

Durante a avaliação de transposição didática elaborada pelos alunos, percebeu-se que alguns grupos tiveram dificuldade em escrever os objetivos geral e específicos, o que está atrelado aos saberes curriculares (TARDIF, 2012). Muitos também exploraram pouco as estratégias antes, durante e depois da leitura. Pôdese perceber que estavam preocupados em desenvolver atividades criativas a partir dos textos oferecidos, mas que não exploravam o ensino da leitura, como propunha a atividade. Outra observação feita foi que os alunos mencionavam que seriam realizados questionamentos durante a leitura, entretanto, esses questionamentos não eram mencionados, nem o momento em que deveriam ser feitos. Todos esses aspectos foram apontados aos alunos e mencionados na devolução, de modo que esse trabalho fosse mais uma forma de aprendizagem. Dos oito grupos, cinco refizeram a transposição e entregaram-na novamente.

Acredita-se ter chamado a atenção dos futuros professores para o fato de que a leitura não envolve apenas decodificação, mas está relacionada a uma série de estratégias, tanto cognitivas como metacognitivas, que precisam ser ensinadas na Educação Básica. 
Conforme mencionado anteriormente, a prática do professor integra diferentes saberes. Assim, ao planejar e executar uma atividade focada no aprimoramento da compreensão leitora dos alunos, o professor leva em conta os saberes experienciais (TARDIF, 2012; PIMENTA, 2005), ou seja, vale-se da experiência com leitura que aquele professor teve como aluno. Se o professor não teve experiências exitosas com estratégias de leitura nas suas experiências, terá mais dificuldades em desenvolvê-las. Daí a importância de trabalhar o tema na licenciatura.

Com relação aos saberes curriculares e disciplinares, também apontados por Tardif (2012), vale a reflexão sobre os conteúdos escolares, os quais dificilmente contemplam compreensão leitora como um conteúdo. Geralmente, esses saberem resumem-se unicamente a pontos gramaticas e a gêneros textuais.

\section{CONSIDERAÇÕES FINAIS}

É indiscutível a necessidade de formar professores de Língua Portuguesa que tenham saberes direcionados para o ensino de compreensão leitora. Além disso, nos programas de formação docente, é preciso abandonar a abordagem tradicional de transmissão de conteúdos gramaticais, que muitos ainda executam objetivando suprir as lacunas dos estudantes, advindas na Educação Básica.

Foi pensando nisso que se elaborou este artigo, o qual objetivou apresentar e analisar uma proposta de formação inicial de professores de Língua Portuguesa voltada para o ensino da compreensão leitora.

A proposta foi desenvolvida na disciplina Psicolinguística, do curso de licenciatura em Letras, ao longo de três aulas. Consistiu, basicamente, nas seguintes atividades: leitura de artigo de revisão, realização da dinâmica peer 
instruction com o apoio do aplicativo socrative, análise das estratégias de leitura em livros didáticos e planejamento de uma transposição didática.

Por fim, a proposta aqui apresentada e as reflexões dela decorrentes, confirmam a hipótese de que a melhora da qualidade da formação dos alunos no que diz respeito à leitura esteja atrelada à qualificação da formação dos professores de Língua Portuguesa. Assim, deve-se continuar olhando para a formação inicial de professores com vistas a capacitá-los e a incentivá-los a também olhar para leitura na perspectiva psicolinguística. Muito provavelmente, esse seja o caminho para melhorar a competência leitora dos alunos.

\section{REFERÊNCIAS}

ALVES, E. V. D. Estratégias de leitura e a (re)significação de uma prática de leitura. 2008. 110 f. Dissertação (Mestrado em Língua Portuguesa) - Pontifícia Universidade Católica de São Paulo, São Paulo, 2008.

ANTUNES, I. Língua, texto e ensino: outra escola possível. São Paulo, SP: Parábola Editorial. 2009.

BEDDINGTON, J.; COOPER, C. L.; FIELD, J.; GOSWAMI, U.; HUPPERT, F. A.; JENKINS, R.; JONES, H. S.; KIRKWOOD, T. B. L.; SAHAKIAN, B. J.; THOMAS, S. M. The mental wealth of nations. Nature, v. 455, n. 23, p. 1057-1060, set., 2008.

BORGES, L F. F. Um currículo para a formação de professores. In: SILVA, F. (Org.). A escola mudou: que mude a formação de professores! 3. ed. Campinas, SP: Papirus, 2011. p. 35-60.

PROVA BRASIL - Avaliação do Rendimento Escolar 2013. Brasília, DF: Instituto Nacional de Estudos e Pesquisas Educacionais Anísio Teixeira. 2013. Disponível em:

$<$ http://download.inep.gov.br/educacao_basica/prova_brasil_saeb/resultados/201 3/caderno_prova_brasil_2013.pdf>. Acesso em: 01 nov. 2015. 
COLOMER, T.; CAMPS, A.; MURAD, F. Ensinar a ler, ensinar a compreender. Porto Alegre, RS: Artmed. 2002.

KATO, M. O aprendizado da leitura. São Paulo, SP: Martins Fontes. 1985.

LAJOLO, M. P. Leitura e Literatura: direito, dever ou prazer? In: LIMA, Aldo. (Org.). O direito à literatura. Recife, PE: Editora Universitária da UFPE, 2013. p. 115-124.

LEFFA, V. J. Aspectos da leitura. Porto Alegre, RS: Sagra-DC-Luzzatto. 1996.

MARTINS NETO, I. A. Estratégias de leitura: relações entre as concepções do material Linguagens, Códigos e suas tecnologias: língua portuguesa e a prática docente. 2015. 159 f. Dissertação (Mestrado em Educação) - Universidade Estadual Paulista, Faculdade de Ciências e Tecnologia, Presidente Prudente, 2015.

MORAIS, J. Criar leitores: para professores e educadores. Barueri, SP: Manole. 2013.

NÓVOA, A. Para una formación de profesores construida dentro de la profesión. Revista de Educación, 350, p. 203-218, set./-dez., 2009. Disponível em:

$<$ http://www.mecd.gob.es/dctm/revista-deeducacion/articulosre350/re35009.pdf?documentId=0901e72b81234820 >. Acesso em: 04 mar. 2016.

OLIVEIRA, L. A. Coisas que todo professor de português precisa saber: a teoria na prática. São Paulo, SP: Parábola Editorial. 2010.

PEREIRA, V. W. Predição leitora e Inferência. In: CAMPOS, J. (Org.). Inferências linguísticas nas interfaces. Porto Alegre: EDIPUCRS, p. 10-22. 2009. Disponível em: <http://www.pucrs.br/edipucrs/inferencias.pdf> Acesso em: 12 set. 2015.

PIMENTA, S. G. A didática como mediação na construção da identidade do professor: uma experiência de ensino e pesquisa na literatura. In: ANDRÉ, M. E.; OLIVEIRA, M. R. N. S. Alternativas no ensino de didática. Campinas, SP: Papirus, p. 37-72. 2005.

RÖSING, T.; ZILBERMAN, R. (Org.). Leitura: história e ensino. Porto Alegre, RS: Edelbra, 2016. 
153

TARDIF, M. Saberes docentes e formação profissional. 4. ed. Petrópolis, RJ: Vozes. 2012.

VEIGA, I. P. A.; VIANA, C. M. Formação de professores: um campo de possibilidades inovadoras. In: SILVA, E. F. (Org.). A escola mudou: que mude a formação de professores! 3. ed. Campinas, SP: Papirus, 2011. p. 13-34.

Recebido: 31 de agosto de 2016

Aceito: 27 de abril de 2017

Publicado: 10 de maio de 2017 